\title{
Um intelectual cosmopolita: trajetórias de Noah Sobe na (história da) educação'
}

\author{
Diana Gonçalves Vidal ${ }^{2}$ \\ ORCID https://orcid.org/0000-0002-7592-0448 \\ Bruno Bontempi Jr. ${ }^{2}$ \\ ORCID https://orcid.org/0000-0002-8524-2652
}

\section{Resumo}

Professor Titular de Estudos em Política Cultural e Educacional na Escola de Educação da Universidade Loyola em Chicago (EUA), Noah W. Sobe é especialista em história da educação, história comparada e educação internacional. Suas pesquisas examinam a circulação global de políticas e práticas educacionais com ênfase particular nas maneiras pelas quais as escolas funcionam como locais de resistência à imposição cultural a pessoas, povos, sociedades e mundos. Interessa-se também por metodologias de pesquisa em educação comparada, especificamente interrogando-se como as noções de contexto, nação, transnacional e globalização/global podem ser reconceitualizadas. Por fim, dedicase ainda à história do afeto e da emoção na educação, com foco na história do tédio na escola. Sua formação e trânsito na arena educativa, bem como as escolhas teóricas e metodológicas são abordadas nesta entrevista, que se estende ainda sobre as relações tramadas com pesquisadores brasileiros associados à Pontifícia Universidade Católica de São Paulo (PUC-SP), à Faculdade de Educação e ao Instituto de Estudos Brasileiros da USP, e explora suas atuais atribuições como Oficial Sênior de Projeto no programa de Pesquisa e Prospecção em Educação da Organização das Nações Unidas para a Educação, a Ciência e a Cultura (UNESCO) junto à iniciativa Futures of Education: Learning to Become ("Futuros da Educação: Aprendendo a se Tornar"). A reflexão abrange também os efeitos da COVID-19 no cenário educativo internacional. Em seu conjunto, o diálogo entabulado oferece ao leitor um leque instigante e atual de problematizações, dentre as quais a inquietante afirmação feita por Noah Sobe de que o "futuro é um fato cultural".

\section{Palavras-chave}

História da educação - História transnacional - História do afeto e da emoção - UNESCO - International Standing Conference for the History of Education (ISCHE).

1- Tradução/versão: Jessé Rebello.

2- Universidade de São Paulo, Faculdade de Educação, São Paulo, SP, Brasil. Contatos: dvidal@usp.br; bontempi@usp.br. 


\section{A cosmopolitan intellectual: the trajectories of Noah Sobe in (the history of) education}

\section{Abstract}

Professor of Cultural and Educational Policy Studies in the School of Education at Loyola University Chicago (USA), Noah W. Sobe specializes in the history of education, and in comparative and international education. His researches examine the global circulation of educational policies and practices with particular emphasis on the ways in which schools work as loci of resistance to the cultural impositions upon individuals, peoples, societies, and worlds. He is also interested in research methodologies in comparative education, investigating specifically how notions such as those of context, nation, transnational and global/globalization can be reconceptualized. Also, he dedicates himself to the history of affect and emotion in education, with focus on the history of boredom in school. His formation and access to the educational arena, as well as his theoretical and methodological choices are examined in this interview, which also discusses his academic connections to Brazilian researchers associated to Pontifical Catholic University of São Paulo (PUCSP), to the School of Education and Institute of Brazilian Studies of the University of São Paulo, and explores his current attributions as Senior Project Officer in the United Nations Educational, Scientific and Cultural Organization (UNESCO) Education Research and Foresight program, part of the Futures of Education: Learning to Become initiative. The reflection also covers the effects of COVID-19 on the international educational scene. As a whole, this dialogue offers the readers a stimulating and contemporary arch of problematizations, among which the disturbing statement made by Noah Sobe that "future is a cultural fact".

\section{Keywords}

History of education - Transnational history - History of affect and emotion - UNESCO International Standing Conference for the History of Education (ISCHE). 


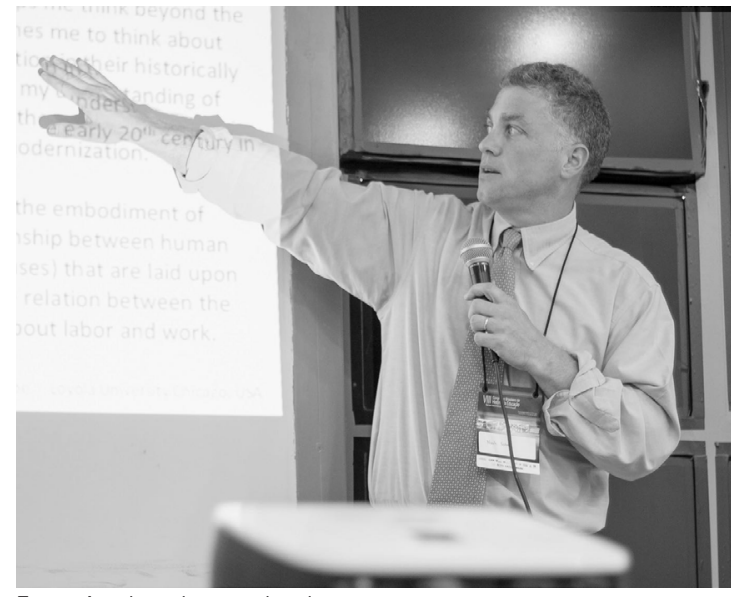

Fonte: Arquivos do entrevistado.

\section{Apresentação}

Professor Titular de Estudos em Política Cultural eEducacional naEscola deEducação da Universidade Loyola em Chicago (EUA), Noah Webster Sobe é especialista em história da educação, história comparada e educação internacional. Atualmente, está licenciado de suas atividades acadêmicas para assumir a posição de Oficial Sênior de Projeto no programa de Pesquisa e Prospecção em Educação da Organização das Nações Unidas para a Educação, a Ciência e a Cultura (UNESCO), Paris, em que colabora com a iniciativa Futures of

Education: Learning to Become ("Futuros da Educação: Aprendendo a se Tornar”). Atua também como pesquisador associado do Projeto Temático "Saberes e práticas em fronteira: por uma história transnacional da educação (1810-...)” (processo FAPESP nr. 2018/266994), liderado por Diana Vidal e Carlota Boto, na Faculdade de Educação em parceria com o Instituto de Estudos Brasileiros da USP.

Dentre suas responsabilidades profissionais anteriores, incluem-se a participação no Comitê Executivo da International Standing Conference on the History of Education (ISCHE) e o mandato como Presidente da seção dos Estados Unidos da América da Sociedade de Educação Comparada e Internacional (Comparative and International Education Society (CIES). Co-edita a revista European Education, afiliada à Sociedade Comparada e Educacional da Europa (Comparative and Education Society of Europe CESE), e integra os conselhos editoriais de várias revistas acadêmicas, incluindo Cadernos de História da Educação. Suas pesquisas examinam a circulação global de políticas e práticas educacionais com ênfase particular nas maneiras pelas quais as escolas funcionam como locais de resistência à imposição cultural a pessoas, povos, sociedades e mundos. Interessa-se também por metodologias de pesquisa em educação comparada, especificamente interrogando-se como as noções de contexto, nação, transnacional e globalização/global podem ser reconceitualizadas. Por fim, dedica-se ainda à história do afeto e da emoção na educação, com foco na história do tédio na escola.

Pela amplitude de sua produção e pelo reconhecimento internacional que Noah Sobe desfruta na comunidade de historiadores da educação, em 2015, participou como convidado do VIII Congresso Brasileiro de História da Educação, ocorrido na cidade de Maringá. Na oportunidade, integrou a mesa-redonda intitulada Arquivos e Fontes na História da Educação, apresentando a comunicação "Fontes, Teorias, Escolarização e Infância: Afeto e Corporeidade nas Escolas Progressistas Norte-Americanas do Amanhã”, posteriormente publicada no livro História da Educação, Matrizes Interpretativas e Internacionalização, organizado por José Gondra, Maria Cristina Machado e Regina Simões para a EdUFES (2017). 
Mesmo antes disso, o historiador da educação estadunidense já era conhecido por suas publicações em português. A primeira delas saiu em 2012, na Revista Brasileira de História da Educação. Tematizava a atuação de John Dewey no entreguerras, fazendo uso do ferramental da história transnacional. 0 artigo foi traduzido ao português por Bruno Bontempi Jr. e revela a colaboração de pesquisa nutrida pelos dois investigadores, antecedendo a disseminação dos trabalhos de Noah Sobe no Brasil.

Quatro anos depois, novo artigo de Sobe era lançado em dossiê organizado por Miriam Jorge Warde para a revista Cadernos de História da Educação. No texto, detinha-se no exame da "atenção" como um objeto de conhecimento relacionado com a organização e gestão de indivíduos, tomando como mote o trabalho de Maria Montessori. Neste segundo caso, os tradutores foram Katya Braghini, Milena Belo e Paulo Jorge de 0. Carvalho, indiciando o forte contato de Noah com o grupo associado ao Programa de Estudos PósGraduados em Educação: História, Política, Sociedade da Pontifícia Universidade Católica de São Paulo (PUC-SP), então capitaneado por Miriam Warde, cujo interesse de longa data sobre as relações entre a história da educação no Brasil e nos Estados Unidos não apenas lhe granjeou a proposição do dossiê, como tem sido um marco de referência sobre a problemática na historiografia educacional brasileira.

0 trânsito nas discussões da história transnacional da educação e o contato com a comunidade de historiadores da educação no Brasil foram fortes condimentos do convite que recebeu para integrar o Projeto Temático da Fundação de Apoio à Pesquisa do Estado de São Paulo (FAPESP) "Saberes e práticas em fronteira: por uma história transnacional da educação (1810-...)”. Com o foco na circulação de sujeitos, de artefatos, de saberes e de práticas entre o Brasil e demais países do mundo, no período que se estende do princípio do século XIX aos dias atuais, o Projeto traz como marco inicial a transferência da Corte portuguesa para o Rio de Janeiro, momento de implantação da primeira imprensa régia em terras brasileiras e de iniciativas que levariam à primeira lei geral do ensino primário, de 1827, e à criação dos cursos secundários e superiores, além das primeiras escolas normais. Estende-se até os dias atuais na compreensão de que as apropriações, intercâmbios, partilhas e trocas de conhecimentos e de ações em nível internacional que se processaram ao longo de dois séculos inscreveram marcas de inovação nas diferentes tradições que compunham e compõem os saberes e as práticas educacionais ainda na atualidade no Brasil.

$\mathrm{Na}$ entrevista que se segue explicitam-se algumas das matrizes teóricas da reflexão de Noah Sobe no âmbito da história da educação, bem como de sua prática política no campo. No que concerne ao primeiro tópico, ganha interesse a discussão dos conceitos de transferência, entanglement e apropriação. De fato, após uma adesão à perspectiva da transferência cultural, o historiador da educação estadunidense passou a criticar o conceito e defender que uma abordagem de história entrelaçada [entangled] "pode ser vantajosamente aplicada para pensar trocas culturais em história da educação" (SOBE, 2012 , p. 16). Isso porque, como assevera nesta entrevista ao responder à sexta pergunta, “que adotar conceitos como os de ‘entrelaçamento' e ‘apropriação' me fornece estratégias mais flexíveis para entender como as pessoas, objetos, princípios e afetos - e até mesmo 'futuros' - foram construídos em dados contextos educacionais e com quais consequências". 
No que tange à sua participação política no campo, Noah destaca, em particular, o incrível dinamismo e criatividade da história da educação não apenas na configuração de novos temas, como na ampliação de seu questionário, na busca por quadros teóricos renovados e no diálogo com demais campos disciplinares.

Mas a conversa entabulada com Sobe abrange outros temas de interesse, não apenas circunscritos aos estudiosos da história da educação. Sua participação recente no projeto Futuros da Educação, criado pela UNESCO, é explorada em detalhe. Particularmente interessante é a sua afırmação do "futuro como um fato cultural", a partir da análise do impacto da COVID-19 na projeção dos novos horizontes. A incursão abarca também uma análise acerca do lugar que as novas tecnologias assumiram no cenário atual e sobre as diferenças de acesso por parte de países e grupos sociais. 0 trabalho na UNESCO favorece, ainda, uma digressão sobre a importância da formação de professores no redesenho do futuro e na compreensão deste mundo contemporâneo marcado pela complexidade, fragilidade e incerteza.

Concluindo a entrevista, uma seleção de artigos publicados em inglês e em português, alguns deles em open access, serve de convite à continuidade do diálogo com este pesquisador engajado com o passado, o presente e o futuro da educação no mundo. Afınal, por seu trânsito entre temas, abordagens, países e instituições, Noah Sobe assume plenamente o caráter de um intelectual cosmopolita. Deixemo-lo, agora, com a palavra.

\section{Referências}

SOBE, Noah W. Entrelaçamentos e troca cultural na história da educação: mobilizando John Dewey no período entre guerras. Revista Brasileira de História da Educação, Maringá, v. 9, n. 3 [21], 2009 [2012], p. 13-38. Disponível em: http://periodicos.uem.br/ojs/index.php/rbhe/article/view/38539. Acesso em: 30 ago. 2020. 


\section{Entrevista}

O senhor recentemente assumiu o cargo de Oficial Sênior de Projeto no programa de Pesquisa e Prospecção em Educação da UNESCO. Conte-nos um pouco sobre esta nova posição e sobre os objetivos que pretende atingir com ela.

É uma verdadeira honra juntar-me à UNESCO, especialmente porque ela é uma organização que tem historicamente desempenhado um importante papel no avanço do direito à educação. Uma das grandes contribuições da UNESCO é que ela tem servido como um laboratório global de ideias e tem trazido importantes perspectivas - por exemplo, em direitos, humanismo e diversidade - para os debates globais contemporâneos sobre educação. E, em um movimento interessante para um historiador da educação, eu mesmo saltei do passado diretamente ao futuro! Tenho estado afastado de minha posição na universidade há dois anos e estou trabalhando em uma nova iniciativa da UNESCO chamada Futuros da Educação: Aprendendo a se tornar. 0 projeto segue os passos do relatório de Faure, de 1972, chamado Learning to be (Aprendendo a ser) e de Delors, de 1996, intitulado Learning, the treasure within (Aprender, o tesouro de dentro). Uma Comissão Internacional foi estabelecida, e essa Comissão publicará um relatório em novembro de 2021.

Há, entretanto, duas diferenças principais entre a iniciativa atual e estes trabalhos prévios da UNESCO. A primeira é que a Comissão é agora encabeçada por Sua Excelência, Madame Sahle-Work Zewde, presidente da Etiópia, o que constitui uma notável diferença em relação a comissões anteriores que eram chefiadas por homens europeus que, inclusive, eram antigos ministros do governo francês. A segunda é que princípios de ampla consulta, engajamento público e compromisso com co-construção estão embutidos na iniciativa Futuros da Educação. Há várias formas para as pessoas se envolverem com o projeto e tenho confiança que a iniciativa terá um impacto muito maior do que se simplesmente envolvesse um relatório escrito por um grupo de 18 pensadores globais, independentemente de quão eminentes ou profundos eles fossem. Já publicamos um livro com pequenos trechos escritos por acadêmicos da UNESCO sobre como a educação pode ter que ser redirecionada e revista para o futuro da humanidade e do planeta. A comissão liberou diversos documentos e fizemos algumas coisas interessantes, como por exemplo lançar uma série de animações de curta metragem que visam catalisar o debate sobre questões-chave para os futuros da educação. Em suma, a visão dessa iniciativa é de que o trabalho da UNESCO sobre os futuros da educação toma a forma de uma conversação em andamento. É um debate e um diálogo que já começaram e precisam continuar para além de 2021.

Em um recente podcast discutindo a iniciativa Futuros da Educação, o senhor mencionou a ideia de que "o futuro é um fato cultural”. Poderia desenvolver mais esse conceito e falar sobre quais tipos de aplicações são antevistas para a educação? 
Creio que a ideia de que "o futuro" existe nas mentes e corações das pessoas tem sido perfeitamente ilustrada pela pandemia da COVID-19, que claramente é mais do que uma crise da saúde, e rapidamente se tornou uma crise econômica, política - e educacional. 0 que mudou com o coronavírus? Com alarmante rapidez, os futuros que havíamos imaginado mudaram. Em outras palavras, tudo que antecipamos que ocorreria na semana, mês ou ano que vem se alterou dramaticamente.

Embora não possamos ignorar o conceito de tempo como um horizonte natural ou científico que contribui para nossa habilidade de distinguir entre passado, presente e futuro, precisamos também pensar sobre o futuro como uma espécie de horizonte cultural. A ideia de que o futuro é um "fato cultural" vem do antropólogo Arjun Appadurai ${ }^{3}$. Esse "futuro", que é saturado de emoção e afetos, é permeado por múltiplos significados e emerge sob diversas formas, tais como aspiração, antecipação e imaginação.

A maneira como as pessoas pensam sobre o futuro é também um problema central para a educação. Tantos de nossos processos educacionais são enquadrados sob a noção de aprender-no-agora para aplicar-e-aproveitar-no-futuro. Na verdade, o "direito a aspirar" é distribuído de forma desigual e injusta no mundo de hoje, como Arjun Appadurai e outros pesquisadores argumentaram. E isso é importante porque a maneira como pensamos, prevemos e buscamos nos preparar e/ou administrar possibilidades e cenários futuros não é uma atividade inócua. É um empreendimento que cria mundos e o mundo.

Um dos maiores desafios que se apresentam aos países do Sul Global é garantir oportunidades iguais de acesso à educação de qualidade. Nestes tempos de quarentena, o emprego de tecnologias de ensino à distância tornou-se essencial. No Brasil, somos confrontados com o fato de que $30 \%$ da população não tem acesso à Internet. Como esta relação entre a necessidade e utilidade de novas tecnologias e a desigualdade estrutural que impede sua disseminação em países como o nosso é considerada dentro do escopo deste projeto?

A crise da COVID-19 tem nos mostrado tanto as promessas das tecnologias de ensino à distância quanto suas fraquezas. E uma das suas desvantagens é a de que diferenças em acesso exacerbam desigualdades. Ao contrário de algumas afırmações otimistas feitas em outros círculos, a Comissão Internacional sobre os Futuros da Educação tem assumido a postura de que uma transição para o ensino à distância não é de forma alguma uma solução universal. Portanto, sim, esta questão que você levanta está sendo abordada diretamente no projeto.

Afora tecnologias de ensino à distância, porém, creio que devemos considerar que meios de conectividade digital precisam ser vistos como parte de um direito expandido à

\footnotetext{
3- Arjun Appadurai, nascido em Bombay, é pesquisador reconhecido por seus estudos culturais da contemporaneidade, notadamente, a respeito das dimensões culturais constitutivas da globalização. Professor de Mídia, Cultura e Comunicação na New York University, e Senior Fellow junto ao Institute for Public Knowledge, foi um dos fudandores da afamada revista Public Culture. Appadurai é autor, entre outras obras, dos livros A vida social das coisas, (EdUFF, 2008), Modernity at Large (1996) e Fear of Small Numbers (2006). Em 2010, a revista Estudos Históricos publicou uma entrevista que concedeu a Bianca Freire-Medeiros e Mariana Cavalcanti: APPADURAI, Arjun. Entrevista com Arjun Appadurai. Estud. hist., Rio de Janeiro, v. 23, n. 45, p. 187-198, June 2010. Available from: http://www.scielo.br/scielo.php?script=sci_arttext\&pid=S010321862010000100009\&lng=en\&nrm=iso. access on: 22 July 2020. https://doi.org/10.1590/S0103-21862010000100009
} 
educação. Isto significa acesso à Internet - não apenas acesso ao professor e às aulas online -, mas conectividade digital vista como essencial para o aprendizado contínuo, para a pesquisa independente e mesmo como parte de um exercício básico do direito à informação.

Uma questão a se ter em mente, entretanto, é a importância contínua e inquestionável da escola como um espaço físico que aproxima os(as) alunos(as) aos(as) professores(as) e a outros(as) em processo de aprendizado. Ao contemplarmos a transformação futura da escola, devemos preservar espaços que tragam as pessoas em co-presença física, bem como a importância de espaços físicos de aprendizado. Muitos perceberam nesta pandemia a importância das escolas como espaços de aprendizado social e emocional; creio que também temos observado (por sua ausência) que as escolas são importantes espaços onde projetos sociais coletivos são levados a efeito.

Porém, combinando o problema de conectividade adequada com o problema de espaços escolares físicos adequados, somos ainda confrontados com o problema da desigualdade estrutural. E, francamente, a questão aqui não é de recursos financeiros - a questão é como os recursos financeiros são distribuídos no mundo de hoje. Considere que nos quatro primeiros meses da crise da COVID-19, o patrimônio líquido do fundador da Amazon aumentou em U\$24 bilhões. Como economistas como Jeffrey Sachs nos lembram, os investimentos necessários para atacar as desigualdades estruturais em educação são, na verdade, bastante pequenos em comparação. Isto pode ser feito por meio de uma melhor governança global; podemos também nos mobilizar para combater desigualdades educacionais começando a levar a solidariedade global a sério. Em vez de tomar 'solidariedade global' como simples palavras que dizemos com facilidade, poderíamos tomá-las como um firme compromisso de nos posicionarmos juntos. E este posicionarmonos juntos precisaria significar que nós não mais aceitaríamos os níveis de desigualdade que têm sido permitidos no nosso mundo.

Como o senhor conecta seus conhecimentos como historiador da educação aos desafios que tem enfrentado na UNESCO? De que maneiras o senhor considera que a educação e os programas de formação de professores podem ser parte dos esforços para moldar o futuro?

A ideia de que "as crianças são o futuro" é um exemplo de um desses "fatos culturais” que estávamos discutindo há pouco. É um importante conceito, entre outras razões, porque tem inspirado muitas pessoas a vir para a área da educação. Para curar e melhorar o mundo, para criar e expandir oportunidades, para fazer o amanhã melhor do que hoje, a educação é uma grande profissão para se ter. E assim, por um lado, ver as crianças como o futuro permite-nos exercer responsabilidades intergeracionais que acredito que temos. Por outro lado, entretanto, há riscos em se relegar as crianças e os jovens ao "futuro". Pode se tornar uma maneira de postergar nossa responsabilidade de agir agora. Uma das mensagens mais claras que vêm do movimento estudantil, e que vemos ganhar força globalmente, particularmente nos protestos estudantis das Fridays for Future (Sextas-feiras para o Futuro), é que moldar o futuro é uma atividade que não deve ser postergada. 
É claro que a ideia de que a educação não deve ser uma preparação para a vida, mas que é importante vivê-la nela mesma, tem uma nobre linhagem no pensamento da educação progressiva (Teixeira, Dewey etc.). Portanto, uma das coisas mais importantes que os programas de formação de professores podem fazer é focar sua atenção nas várias formas em que as pessoas "usam" o futuro quando pensam sobre métodos educacionais básicos, quando definem currículos e quando conceitualizamos os propósitos das escolas e de outros espaços de aprendizado organizado.

De fato, embora pareça contraintuitivo, estudar a história da educação pode ser uma das maneiras mais efetivas de tornar professores e futuros professores mais "alfabetizados sobre o futuro". Aprender sobre as formas como professores e escolas "usaram o futuro" no passado distante e não tão distante tem um grande potencial para despertar a autoconsciência sobre como "usamos o futuro" agora.

Para mim, ser um historiador da educação me tornou particularmente sensível à especificidade contextual das maneiras como professores e sistemas de educação baseiam seus esforços em teorias de mudança e em noções específicas de como o agir no presente conduzirá (ou "deveria" conduzir) a resultados futuros. Por muito tempo, sistemas educacionais modernos abordaram essa questão como a de controlar as probabilidades, como a tarefa de produzir os modelos preditivos mais confiáveis para "engendrar" futuros desejados. Entretanto, parece estar se tornando cada vez mais claro que a incerteza é um fato da vida que resiste a ser facilmente controlada - e creio que muitas pessoas veem acertadamente a COVID-19 como tendo ensinado exatamente este tipo de lição.

A certeza da incerteza tem, assim, grandes implicações para a educação e para a formação de professores. Confrontados com o conhecimento de que o mundo de hoje é marcado pela complexidade, fragilidade e incerteza, eu diria que nós provavelmente precisamos de uma grande ênfase em diversidade, flexibilidade, engenho, resiliência e adaptabilidade em nossas abordagens educacionais, e provavelmente precisamos ajustar nesse sentido muitos de nossos programas de formação de professores.

Pode-se dizer que John Dewey ainda está na moda e que é sempre controverso. Baseado no seu próprio trabalho, quais o senhor considera que são as razões para estas discussões duradouras no campo educacional a respeito das ideias de Dewey?

As discussões sobre Dewey são duradouras, eu concordo. Porém, assim como "Dewey" entra no debate pedagógico de diferentes formas em diferentes lugares, "Dewey" muda com o tempo. Eu diria que para mim, neste momento, as ideias de Dewey acerca da coisa pública, particularmente da forma como Maxine Greene as desenvolveu em relação à educação, têm bastante a oferecer ao nosso pensamento sobre educação ${ }^{4}$. Simplesmente creio que Dewey é um interlocutor útil, mas claro que nem sempre e certamente não em todos os tempos e lugares.

4- Maxine Greene é Professora Emérita do Teachers College, da Columbia University, é especialista em Filosofia da Educação, com ênfase na Estética e na Arte na formação de professores. Para mais Informações sobre a vida e a obra de Maxine Greene, consultar www.maxinegreene.org 
Com relação especificamente ao campo da História da Educação, no qual o senhor tem desempenhado um papel proeminente como pesquisador e como membro de sociedades científicas, poderia resumir as principais tendências que o senhor vê ao redor do mundo (os tópicos, perspectivas e metodologias mais recorrentes)?

Vejo incrivel dinamismo e criatividade na história da educação, especialmente na medida em que pesquisadores descobrem como estudar tendências e fenômenos que tempos atrás nunca pareciam ser tópicos legítimos de investigação histórica. Estou pensando aqui, por exemplo, no trabalho que está sendo feito sobre emoções e afeto, sobre práticas educacionais cotidianas e sobre objetos, corporeidade e relacionamentos. Em parte, isso ocorre porque o campo está se movendo para além dos relatos de crônicas. Em parte, é porque o jugo das abordagens excessivamente estreitas à história social tem abrandado. 0 campo se move para além de classe e raça como lentes sine qua non e, por exemplo, tornase cada vez mais comum para pesquisadores historicizarem suas categorias analíticas à medida que desenvolvem seu trabalho.

Penso também que estamos observando um bem-vindo abrandamento do nacionalismo metodológico. Isto não significa ignorar o estado-nação, mas sim não tomálo como uma categoria dada como certa. Finalmente, mencionaria que há interessantes desenvolvimentos no que por vezes se denomina "história pública", frequentemente com arquivos e museus tomando a frente neste processo. Historiadores de profissão têm um importante papel a jogar, mas cada vez mais temos que conectar nosso trabalho à história pública e ao papel que as compreensões do passado desempenham na vida das pessoas.

Pesquisas em História da Educação têm mostrado que modelos/ideias viajam o mundo e têm impacto em realidades nacionais. De que forma conceitos como transferência, entrelaçamento e apropriação nos ajudam a entender este fenômeno no passado e no presente? Poderia nos dar exemplos disso?

Partindo das observações que acabo de fazer sobre o trabalho acadêmico que escapa aos limites do nacionalismo metodológico, eu diria que o trabalho acadêmico em transnacionalismo e história global é umas das áreas mais estimulantes no momento. 0 fardo do trabalho nesta área não é, porém, pequeno. Pesquisa em história transnacional normalmente requer trabalho em arquivos com múltiplas localizações, bem como proficiência em diversas línguas.

0 trabalho acadêmico transnacional mostra claramente os perigos do essencialismo e nos estimula a enxergar nosso trabalho como uma pesquisa sobre conjuntos contingentes, provisionais e heterogêneos. No meu próprio trabalho sobre circulações globais de práticas e políticas educacionais, não achei o conceito de "transferência" particularmente útil - pelo fato de que ele sugere certa nitidez ou "pureza" de origens e destinações que simplesmente não parecem existir na maioria dos casos. As assim chamadas realidades nacionais não são homogêneas e causamos mais mal do que bem quando as essencializamos. No meu trabalho, tenho observado que adotar conceitos como os de "entrelaçamento" e "apropriação" me fornece estratégias mais flexíveis para entender como as pessoas, objetos, princípios e 
afetos - e até mesmo "futuros" - foram construídos em dados contextos educacionais e com quais consequências.

0 senhor mencionou a mudança que fez em seu trabalho do paradigma da transferência para os conceitos de entrelaçamento e apropriação. Poderia nos dar alguns exemplos do impacto desta abordagem metodológica em sua pesquisa?

Deixe-me dar um exemplo extraído da historiografia educacional norte-americana. Por certo tempo, houve uma estória mal desenhada de que as primeiras escolas no que veio a se tornar os Estados Unidos da América, as escolas de vila da Nova Inglaterra organizadas por líderes Puritanos civis e religiosos, eram uma "transferência" de um modelo escolar da Inglaterra. Houve então um segundo capítulo dessa estória que começou no início do século XIX com a forma de escolarização que veio a se tornar o "modelo escolar comum", a qual, em uma versão da estória, também representava uma "transferência”, por exemplo, dos modelos de Bell-Lancaster e também do famoso exemplo Prussiano. Na narrativa tradicional, a primeira delas foi uma localização malsucedida: as escolas Puritanas mostraram-se "inadequadas" às novas condições. Enquanto isso, a segunda transferência teria sido uma indigenização adequada, uma reorganização de modelos 'mais apropriados' à democracia Americana, à vida cívica (e à expansão imperialista, pode-se acrescentar).

Um dos problemas deste enquadramento é que ele essencializa as práticas escolares, tanto nos contextos de uma suposta "origem", quanto nos contextos de "destinação". Como uma disciplina, a história pode ser extremamente boa para capturar a complexidade. Para mim, paradigmas de transferência representam uma tentativa de produzir um modelo teórico simplificado que não se sustenta diante das evidências empíricas. Ele pode, por vezes, ser útil como uma forma abreviada de se referir a modelos e, é claro, pode ser bastante relevante em situações onde os próprios agentes históricos pensam em termos de "modelos" e modelagem. Porém, este movimento pode nos fazer pensar erroneamente que existem lógicas sobrejacentes e fatores determinantes da mudança histórica. A meu ver, há considerável contingência e circunstâncias cegas - e algo como o "movimento pela escola comum" nos EUA ilustra bem este fato. 0 rótulo de "comum" foi certamente discutido na época (podemos pensar no chamamento de Thoreau por escolas "incomuns", por exemplo), mas não devemos esquecer que estas escolas também foram discutidas como escolas "livres" e que a estruturação da escolaridade nos EUA em meados do século XIX também se entrecruzava com preocupações sobre abolicionismo e relações raciais; trabalho em uma sociedade em industrialização e uma reelaboração do nexo entre trabalho e lazer; e também o que poderíamos chamar em um vocabulário foucaultiano de uma biopolítica sobre a participação política e a governança. Em suma, observo que uma abordagem baseada em entrelaçamento e montagem é mais produtiva para tornar compreensivel a heterogeneidade e complexidade do que uma abordagem baseada em acompanhar linhagens e adaptações.

O senhor participou do Congresso Brasileiro de História da Educação em 2015 como parte de sua colaboração em pesquisa com historiadores da educação brasileiros, 
a qual envolve a participação em projetos de pesquisa. Como esta experiência impactou sua visão deste campo de estudos? Quais ganhos mútuos o senhor observa aqui?

A comunidade brasileira de história da educação tem sido uma inspiração! De fato, participei de diversas conferências de história no Brasil. 0 tamanho e a abrangência da história da educação no Brasil são vastos. Trabalhar com historiadores da educação brasileiros em projetos de pesquisa e receber pesquisadores de doutorado tem alargado e trazido nuances ao meu entendimento da história transnacional e global.

\section{Bibliografia recente do entrevistado}

SOBE, Noah W. Boredom and classroom design: the affective economies of school engagement. In: GROSVENOR, lan; RASMUSSEN, Lisa Rosén (ed.). Making education: governance by design. New York: Springer, 2018. p. 157-182.

SOBE, Noah W. Problematizing comparison in a post-exploration age: big data, educational knowledge, and the art of criss-crossing. Comparative Education Review, v. 62, n. 3, p. 325-343, Aug. 2018. https://doi.org/10.1086/698348

SOBE, Noah W. Travelling researchers, colonial difference: comparative education in an age of exploration. Compare, v. 47, n. 3, p. 332-343, 2017. http://dx.doi.org/10.1080/03057925.2016.1273760

\section{Bibliografia em português do entrevistado}

SOBE, Noah W. Desafiando o olhar: o sujeito da atenção e uma sala de aula de demonstração montessoriana, 1915. Cadernos de História da Educação, Uberlândia, v. 15, n. 1, p. 166-189, 2016. http://www.seer.ufu.br/index.php/ che/ article/view/34631

SOBE, Noah W. Entrelaçamentos e troca cultural na história da educação: mobilizando John Dewey no período entre guerras. Revista Brasileira de História da Educação, Maringá, v. 9 , n. 3 [21], 2009 [2012], p. 13-38. Disponível em: http://periodicos.uem.br/ojs/index.php/rbhe/article/view/38539. Acesso em: 30 ago. 2020.

SOBE, Noah W. Fontes, teorias, escolarização e infância: afeto e corporeidade nas escolas progressistas NorteAmericanas do amanhã = Sources, theory, schooling, and childhood: affect and embodiment in American progressive schools of to-morrow. L. A. Gomes Senna (Trans.). In: GONDRA, José Gonçalves; MACHADO, Maria Cristina Gomes; SIMOES, Regina Helena Silva (ed.). História da educação, matrizes interpretativas e internacionalização. Vitória: Edufes, 2017. p. 273-296. 